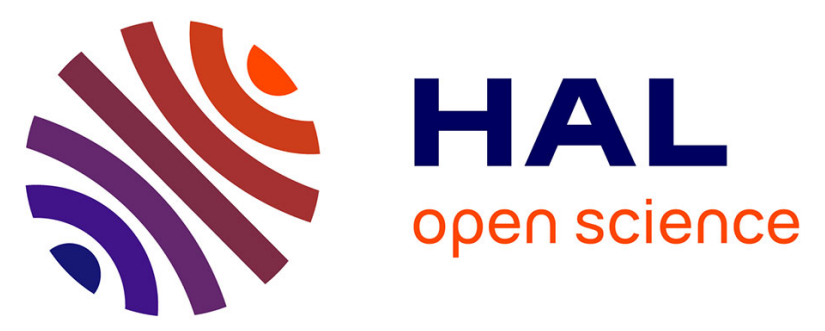

\title{
Chlorine measurements at the 5MV French AMS national facility ASTER: Associated external uncertainties and comparability with the $6 \mathrm{MV}$ DREAMS facility
}

R. Braucher, K. Keddadouche, G. Aumaître, D.L. Bourles, M. Arnold, S. Pivot, M. Baroni, A. Scharf, G. Rugel, E. Bard

\section{To cite this version:}

R. Braucher, K. Keddadouche, G. Aumaître, D.L. Bourles, M. Arnold, et al.. Chlorine measurements at the 5MV French AMS national facility ASTER: Associated external uncertainties and comparability with the 6MV DREAMS facility. Nuclear Instruments and Methods in Physics Research Section B: Beam Interactions with Materials and Atoms, 2018, 420, pp.40 - 45. 10.1016/j.nimb.2018.01.025 . hal-01705927

\section{HAL Id: hal-01705927 \\ https://hal.science/hal-01705927}

Submitted on 3 Feb 2022

HAL is a multi-disciplinary open access archive for the deposit and dissemination of scientific research documents, whether they are published or not. The documents may come from teaching and research institutions in France or abroad, or from public or private research centers.
L'archive ouverte pluridisciplinaire HAL, est destinée au dépôt et à la diffusion de documents scientifiques de niveau recherche, publiés ou non, émanant des établissements d'enseignement et de recherche français ou étrangers, des laboratoires publics ou privés. 
Elsevier Editorial System(tm) for Nuclear

Inst. and Methods in Physics Research, B

Manuscript Draft

Manuscript Number: V1586R1

Title: Chlorine measurements at the 5 MV French AMS national facility ASTER: associated external uncertainties and comparability with the 6MV DREAMS facility.

Article Type: Full Length Article

Keywords: Accelerator mass spectrometry, Chlorine, Standard, Cosmogenic nuclides

Corresponding Author: Dr. Régis Braucher,

Corresponding Author's Institution:

First Author: Régis Braucher

Order of Authors: Régis Braucher; Karim Keddadouche; Georges Aumâ̂tre; Didier L Bourlès; Maurice Arnold; Sébastien Pivot; Mélanie Baroni; Andreas Scharf; Georg Rugel; Edouard Bard

Abstract: After 6 years of $36 \mathrm{Cl}$ routine operation, more than 6000 unknown samples have been measured at the 5 MV French accelerator mass spectrometry (AMS) national facility ASTER (CEREGE, Aix en Provence). This paper presents the long term behavior of ASTER through the analysis of the measurements of the most used chlorine standards and reference materials, KNSTD1600, SM-Cl-12 and SM-CL-13 over a 46 months' time period.

Comparison of measured chlorine concentrations (both 35Cl and 36Cl) from ice samples on two AMS facilities operating at 5MV (ASTER) and 6MV (DREAMS, Helmholtz-Zentrum Dresden-Rossendorf) and normalizing to two different reference materials agree within uncertainties making both reference materials (SM-Cl-12 and KNSTD1600) suitable for 36Cl

measurement at ASTER. 
1 Chlorine measurements at the 5 MV French AMS national facility ASTER: associated external uncertainties and comparability with the 6MV DREAMS facility.

$3 \frac{1}{2}$

3

44

5

$5 \begin{aligned} & 6 \\ & 7\end{aligned}$

68 10

711

12

13

814 15

916

18

$10_{19}^{18}$ 20

1121

22

$12^{23}$

25

1326

27

28

$14_{30}^{29}$

31

1532

1633

1634

$17_{36}^{35}$

1837

1939

40

2041 Comparison of measured chlorine concentrations (both ${ }^{35} \mathrm{Cl}$ and ${ }^{36} \mathrm{Cl}$ ) from ice samples on two AMS facilities 42

2143

2244

$23 \frac{46}{47}$

48

2449

51

2552

53

54

55

56

57

58

59

60

61

62

63

64

65

R. Braucher ${ }^{1}$, K. Keddadouche ${ }^{1,2}$, G. Aumaître ${ }^{1,2}$, D.L. Bourlès ${ }^{1,2}$, M. Arnold ${ }^{1,2}$, S. Pivot ${ }^{1}$, M. Baroni ${ }^{1}$, A. Scharf $^{3}$, G. Rugel ${ }^{3}$, E. Bard ${ }^{1}$.

${ }^{1}$ Aix Marseille Univ., CNRS, IRD, Coll. France, CEREGE, Plateau de l'Arbois, BP 80, 13545 Aix en

Provence, France

ASTER-Team, Aix Marseille Univ., CNRS, IRD, Coll. France, CEREGE, Plateau de l'Arbois, BP 80, 13545

Aix en Provence, France

Helmholtz-Zentrum Dresden-Rossendorf, Helmholtz Institute Freiberg for Resource Technology, Bautzner andstr. 400, 01328. Dresden, Germany

Corresponding author: Régis Braucher; Tel +33442971509; braucher@cerege.fr

Abstract:

After 6 years of ${ }^{36} \mathrm{Cl}$ routine operation, more than 6000 unknown samples have been measured at the $5 \mathrm{MV}$ French accelerator mass spectrometry (AMS) national facility ASTER (CEREGE, Aix en Provence). This paper presents the long term behavior of ASTER through the analysis of the measurements of the most used chlorine standards and reference materials, KNSTD1600, SM-Cl-12 and SM-CL-13 over a 46 months' time period.

operating at 5MV (ASTER) and 6MV (DREAMS, Helmholtz-Zentrum Dresden-Rossendorf ) and normalizing to two different reference materials agree within uncertainties making both reference materials (SM-Cl-12 and KNSTD1600) suitable for ${ }^{36} \mathrm{Cl}$ measurement at ASTER.

Keywords: Accelerator mass spectrometry, Chlorine, Standard, Cosmogenic nuclides. 


\section{Introduction}

281 In April 2017, ASTER, the 5MV French Accelerator Mass Spectrometry (AMS) national facility hosted by

292

$30 \begin{aligned} & 4 \\ & 5\end{aligned}$

316

328

3310 11

3412

3513

$36_{16}^{15}$

$37_{18}^{17}$

$38^{19}$ 20

3921

22

4023

24

$41_{25}^{24}$

$42_{27}^{26}$

$43_{29}^{28}$

4430

4532 33

4634

$47 \stackrel{35}{36}$

$48_{38}^{37}$

$49^{39}$

40

5041
42

5143

44

5245

5346

$54_{49}^{48}$

$55_{51}^{50}$

5652

5754

55

5856

5958

6059

$61^{61}$ 62

6263
64 65

CEREGE in Aix-en-Provence will pass a decade since the acceptance tests. Since then, ASTER is routinely measuring ${ }^{10} \mathrm{Be}$ and ${ }^{26} \mathrm{Al}[1,2]$. The ions extracted from a SO110 hybrid ion source [3]are first energyanalysed by a 54 degree electrostatic deflector before being mass-analyzed by a 90 degree magnet equipped with a fast bouncing system that sequentially injects the isotopes of interest with a repetition rate of $\sim 100 \mathrm{~Hz}$. A fast beam blanking unit defines with nanosecond resolution the exact duration during which the different isotopes are injected through the accelerator. The HVE model 4150 Tandetron TM accelerator [4] is equipped with an all-solid-state power supply. The high energy-spectrometer features a 90 degree analyzing magnet with Faraday cups installed for measurement of the stable isotopes. Faraday cups are followed by SiN absorber foil and a 35 degree electrostatic deflector. Two sets of Q-pole doublets just before and after the electrostatic deflector serve for proper focusing of the beam that suffers from substantially emittance growth by scattering in the foil. A 30 degree magnet reduces background from ions that have been scattered on the deflector electrodes. The magnet is mounted vertically to uncouple the dispersive action of the electrostatic deflector and the magnet. The measurement of all isotopes is gated in synchronization with their corresponding injection periods. The rare isotope is detected in a high-resolution, 4-anode gas ionization chamber.

Because regarding volatile elements $\left({ }^{36} \mathrm{Cl},{ }^{129} \mathrm{I}\right)$ the initial Cs-sputter ion source $\mathrm{SO} 110$ induced sample-tosample cross-contamination, the source and aperture designs as well as the shape of the cathodes have been upgraded to reduce the resulting memory effects to significantly less than $\sim 0.1 \%$, allowing routine measurements of these volatile elements [4,5] since 2010. More specifically, an average number of $1000{ }^{36} \mathrm{Cl}$ unknown targets are measured per year, all being normalized to $\mathrm{AgCl}$ materials (KNSTD1600; ${ }^{36} \mathrm{Cl} /{ }^{35} \mathrm{Cl}=2.112 \times 10^{-12}$ ) prepared by Kuni Nishiizumi [6]. To monitor the long term variability of ASTER and to determine the external uncertainties associated to the ${ }^{36} \mathrm{Cl}^{35} \mathrm{Cl},{ }^{36} \mathrm{Cl} /{ }^{37} \mathrm{Cl}$ and ${ }^{35} \mathrm{Cl} /{ }^{37} \mathrm{Cl}$ ratios, it has be decided to measure together with the KNSTD1600 standard, the SM-Cl-X reference materials. Prepared by S. Merchel under the auspice of the European project "CRONUS-EU", these SM-Cl-X reference materials have been cross-calibrated through an interlaboratory comparison involving eight AMS facilities worldwide. The resulting round-robin data are fully presented in Merchel et al. (2011) [7]. The aim of this paper is therefore not to refine the SM-Cl-X standards calibration with more data points but to quantify the external uncertainties associated to chlorine measurements at the 5MV French Accelerator Mass Spectrometry (AMS) national facility ASTER. These measurements also aimed at replacing the KNSTD1600 standard whose availability is not guaranteed in the long term, by the SM-Cl-X reference materials. In order to confirm the change of reference material after a 46-month period of measurements of SM-Cl-X vs. KNSTD1600 at ASTER, an inter comparison has been conducted on an identical batch of samples measured ${ }^{36} \mathrm{Cl}$ concentrations measured in the same ice samples both at ASTERand at DREAMS, the 6MV AMS-facility hosted by the HDZR Ion Beam Center in Dresden $[8,9,10]$ (Table 1)are then compared for these two AMS 
facilities working at different energies and provide results normalized to different standards (KNSTD1600 for

ASTER, SMCl-XX for DREAMS. For this inter comparison, modern snow samples from Antarctica have

65

662

674

68 年

686

$69 \begin{aligned} & 7 \\ & 8\end{aligned}$

709

7111

12

7213

$73_{15}^{14}$

$74 \frac{16}{17}$

$75^{18}$

7620 21

7722

7823

7824

$79_{26}^{25}$

$80_{28}^{27}$

8129

8231

32

8333

8435

$85^{36}$

$86_{39}^{38}$

8740

41

8842

43

8944

9045

$91_{48}^{47}$

9249

9351

9453 54

9555

9656

$97^{58}$

9860

9962

63

64

65

\section{Chlorine measurements at ASTER.}

At ASTER, chlorine measurements are performed as explained hereafter:

\section{Standardization:}

- 3 to 4 cathodes of KNSTD1600 standard are measured per batch. Each cathode is measured three times 10 minutes divided in 20 blocks of 30 seconds each. The first 2 minutes of each measurement period are discarded since they may potentially be affected by memory effects. Typical ${ }^{35} \mathrm{Cl}$ currents are ranging from 25-30 $\mu \mathrm{A}$ and regarding ${ }^{36} \mathrm{Cl}, 7.000$ to 15.000 events are detected.

- At the end of the batch, the three individual measurements performed on each KNSTD1600 cathode are statistically compared (using a Chi2 test following [11]) and recombined to provide the measured ${ }^{36} \mathrm{Cl} /{ }^{35} \mathrm{Cl}$, ${ }^{36} \mathrm{Cl} /{ }^{37} \mathrm{Cl}$ and ${ }^{35} \mathrm{Cl} /{ }^{37} \mathrm{Cl}$ ratios associated to each KNSTD1600 cathode. Considering then the 3 to 4 different KNSTD1600 standard cathodes, their respective ratios are compared following the same Chi2 test and a weighted mean is calculated that allows determining the machine response and the correction factor to apply to back calculate the ratios associated to the samples to be measured (three corrections factors are thus determined, one for ${ }^{36} \mathrm{Cl} /{ }^{35} \mathrm{Cl}$, one for ${ }^{36} \mathrm{Cl} /{ }^{37} \mathrm{Cl}$, and one for ${ }^{35} \mathrm{Cl} /{ }^{37} \mathrm{Cl}$ ).

\section{Unknown measurements.}

Samples are measured three times 20 minutes divided in 40 blocks of 30 seconds each. Similarly, the first 2 minutes of each measurement period are discarded and the three measurements (20 minutes each) are compared and recombined to provide ${ }^{36} \mathrm{Cl} /{ }^{35} \mathrm{Cl},{ }^{36} \mathrm{Cl} /{ }^{37} \mathrm{Cl}$ and ${ }^{35} \mathrm{Cl} /{ }^{37} \mathrm{Cl}$ ratios that are finally multiplied by the previously determined correction factors to obtain the sample ${ }^{36} \mathrm{Cl} /{ }^{35} \mathrm{Cl},{ }^{36} \mathrm{Cl} /{ }^{37} \mathrm{Cl}$ and ${ }^{35} \mathrm{Cl} /{ }^{37} \mathrm{Cl}$ ratios. The previously described procedure is the procedure by default used for the majority of the samples. Highly ${ }^{36} \mathrm{Cl}$ concentrated samples implying a significantly higher counting statistics may only be measured three times 5 minutes divided in 15 blocks of 20 seconds each.

Together with standards and unknown samples, one background cathode filled with a natural chlorine carrier with a low ${ }^{36} \mathrm{Cl}$ content is measured to monitor the cleanliness of the ion source $\left({ }^{36} \mathrm{Cl} /{ }^{35} \mathrm{Cl}<3.10^{-15}\right)$ 
From February 2013 to December 2016, SM-Cl-12 and SM-Cl-13 reference materials were measured together with the KNSTD1600 standard. As the internationally cross-calibrated SM-Cl-12 reference material may eventually be considered as a substitute for KNSTD1600, an equivalent number of SM-Cl-12 and KNSTD1600 cathodes were measured. In addition, one SM-Cl-13 cathode was measured per batch as SM-Cl3

104413 will be used to monitor the long term stability of ASTER. Over the covered time period, this represents 5 1056189 cathodes of SM-Cl-12 and 31 cathodes of SM-Cl-13 measured.

$106{ }_{8}^{7}$ Assuming a Gaussian distribution centered on the mean, cumulative distribution functions ordering the $107 \begin{array}{r}9 \\ 10\end{array}$ $108 \frac{11}{12}$ (Fig. 1) and the SM-Cl-13/KNSTD1600 (Fig. 2) ratios considering all ${ }^{36} \mathrm{Cl} /{ }^{35} \mathrm{Cl},{ }^{36} \mathrm{Cl} /{ }^{37} \mathrm{Cl}$ and ${ }^{35} \mathrm{Cl} /{ }^{37} \mathrm{Cl}$ 10913 individual measurements. All ratio measurements (SM-Cl-12/KNSTD1600 and SM-Cl-13/KNSTD1600) are 14 presented in the Supplementary Material (Sup Table 1).

The distribution function used is $\mathrm{F}(\mathrm{x}, \mu$, sigma $)=\frac{1}{\sqrt{2 \pi \sigma}} e^{\left[\frac{(x-\mu)^{2}}{(2 \sigma)^{2}}\right]}$ where $\mathrm{x}$ is the ratio $\left({ }^{36} \mathrm{Cl} /{ }^{35} \mathrm{Cl},{ }^{36} \mathrm{Cl} /{ }^{37} \mathrm{Cl}\right.$ or ${ }^{35} \mathrm{Cl} /{ }^{37} \mathrm{Cl}$ )for which we are looking for the distribution; $\mu$, the mean; and $\sigma$, the standard deviation. The mean standard error is calculated as follows: mean standard error $=\sqrt{\left[\frac{\text { stand.dev. }}{\sqrt{\text { Number of measur. }}}\right]^{2}}$ (Table 2). When all $\mathrm{SM}-\mathrm{Cl}$-X / KNSTD1600 ratios for each isotopic ratio $\left({ }^{36} \mathrm{Cl} /{ }^{35} \mathrm{Cl},{ }^{36} \mathrm{Cl} /{ }^{37} \mathrm{Cl}\right.$ and $\left.{ }^{35} \mathrm{Cl} /{ }^{37} \mathrm{Cl}\right)$ are taken into account, they do not satisfy the Chi2 test for none of the three ${ }^{36} \mathrm{Cl} /{ }^{35} \mathrm{Cl},{ }^{36} \mathrm{Cl} /{ }^{37} \mathrm{Cl}$ and ${ }^{35} \mathrm{Cl} /{ }^{37} \mathrm{Cl}$ ratios (Table 2).

To make all these isotopic ratios satisfy the Chi2 test, an external machine error has thus to be added to the analytical uncertainties (counting statistics + variability of the standard during the batch). Contrary to ${ }^{10} \mathrm{Be}$ and ${ }^{9} \mathrm{Be}$, yielding to one isotopic ratio and thus to one external machine error, this has to be done in the peculiar case of chlorine for the three isotopic species yielding to 3 isotopic ratios. For SM-Cl-12, all SM-Cl12/KNSTD1600 ratios belong to the same population for a given isotopic ratio providing that an external uncertainty of $2.74 \%, 2.13 \%$ and $1.62 \%$ is added to the analytical uncertainties for ${ }^{36} \mathrm{Cl} /{ }^{35} \mathrm{Cl},{ }^{36} \mathrm{Cl} /{ }^{37} \mathrm{Cl}$ and ${ }^{35} \mathrm{Cl} /{ }^{37} \mathrm{Cl}$ ratios, respectively. Regarding SM-Cl-13, all SM-Cl-13/KNSTD1600 ratios belong to the same population for a given isotopic ratio providing that an external uncertainty of $2.06 \%, 2.31 \%$ and $1.58 \%$ is added to the analytical uncertainties for ${ }^{36} \mathrm{Cl} /{ }^{35} \mathrm{Cl},{ }^{36} \mathrm{Cl} /{ }^{37} \mathrm{Cl}$ and ${ }^{35} \mathrm{Cl} /{ }^{37} \mathrm{Cl}$ ratios, respectively (Table 3, 4).

To our knowledge, the determined external uncertainties presented above are the first one reported for an AMS facility working at such low ion energy $(\sim 30 \mathrm{MeV})$ and using a post stripping degrade. They are in agreement with those presented by the SUERC group using a different AMS technology but working at the same energy. SUERC group has proposed uncertainties of $\sim 3 \%$ and $1.5 \%$ for ${ }^{36} \mathrm{Cl} / \mathrm{Cl}$ ratios and stable chlorine measurements respectively [12]. These numbers were reached after 3 years measurements of a secondary standard (KNSTD 5.0x10 13 ).

External uncertainty associated to the ${ }^{36} \mathrm{Cl} /{ }^{35} \mathrm{Cl}$ ratio on the order of $3 \%$ might be considered as high. However, one has to keep in mind that: a/ the 5MV required to reach the charge state $5+$ for chlorine 62 13463 represents the upper working limit for ASTER; and, b/ an as efficient as possible isobaric separation relies at 
ASTER on post-stripping which implies the use of a degrader foil installed behind the focal plane of the $90^{\circ}$ high energy magnet combined with a strict energy selection (see [2, 13] for more details). These working conditions imply that although the region of interest (ROI) corresponding to the ${ }^{36} \mathrm{Cl}$ and its interfering isobar, $2{ }^{36} \mathrm{~S}$, are carefully defined after a conditioning of the accelerator tube without gas stripper and a subtle tuning 3

394 of the facility (Cs-beam focus, magnetic fields, Einzel lenses, electrostatic deflectors),, at 5 MV the difference

1406 in energy loss of the two isobars ${ }^{36} \mathrm{Cl}-{ }^{36} \mathrm{~S}$ is small compared to the total energy loss. Therefore, the lowest

$141{ }_{8}^{7}$ energy post-stripping ${ }^{36} \mathrm{~S}^{10+}$ ions may have energy similar to the highest energy post-stripping ${ }^{36} \mathrm{Cl}^{10+}{ }^{10 n s}$.

1429 Therefore, both isobars are not perfectly separated in the electrostatic and magnetic analyzers following the degrader foil and preceding the $\Delta \mathrm{E}-\mathrm{E}$ gas ionization detector and their respective ROI are not well dissociated. Consequently, before starting a new measurement batch ( every 2 days), all the tunings have to 14 14515 16 14617 $147 \frac{18}{19}$ be updated to take into account the degrader foil deterioration, the temperature fluctuation, etc. Despite these limiting conditions, standard variations within a single batch are typically less than $1.5 \%$. The $2.74 \%$ external error associated to the ${ }^{36} \mathrm{Cl} /{ }^{35} \mathrm{Cl}$ ratio measurement determined over a 46 months period (56 batches) appears thenceforth acceptable.

\section{Measurements of ice test samples on two AMS: the 5MV ASTER and the 6MV DREAMS.}

Considering the previously discussed limitations induced by the ASTER terminal voltage, it appeared necessary to compare chlorine measurements performed at ASTER with chlorine measurements performed at other operating facilities. An inter comparison on both ${ }^{36} \mathrm{Cl}$ and $\mathrm{Cl}$ concentrations measured in snow samples was thus conducted on two different AMS facilities: the 5MV ASTER and the 6MV DREAMS. Historically ${ }^{10}$ Be has been measured in ice cores to document past solar activity $([14,15,16]$ and geomagnetic excursions $[17,18]$. Such deposits consisting of a chemically simple and clean substrate accumulate at rates high enough to allow high resolution records which may sometimes reach an annual resolution [19]. However, ${ }^{10} \mathrm{Be}$ deposition may also be influenced by phenomenon not related to the heliomagnetic or geomagnetic modulations such as volcanic eruptions and atmospheric circulation [20]. Comparison between different cosmogenic nuclides having their own geochemical cycle and deposition behavior is then a means to significantly improve our understanding of the processes governing the modulation of their production rate in the atmosphere. In this context, ${ }^{36} \mathrm{Cl}$ concentration measurements in ice cores have been developed at CEREGE in order to complement the ${ }^{10}$ Be ones.

In order to valid the sample preparation methods as well as the ${ }^{36} \mathrm{Cl}$ concentration measurement from snow and ice developed at CEREGE, an inter-comparison between the measurements performed at ASTER (CEREGE) and DREAMS (HDZR Ion Beam Center, Dresden) has been conducted. Besides ${ }^{36} \mathrm{Cl}$ concentrations obtained from ${ }^{36} \mathrm{Cl} /{ }^{35} \mathrm{Cl}$ ratio measurements, the natural chloride concentrations can be 58 16959 17060 
samples of the 14 specifically prepared for both ASTER and DREAMS measurements to test the reliability of the ${ }^{36} \mathrm{Cl}$ concentrations measured from snow (or ice) samples with low natural $\mathrm{Cl}^{-}$concentration.

1

2 3

1754 5

1766

$777^{7}$

1778

$178^{9}$

17911

18013

14

18115

16

18217

$183^{18}$

$184^{20}$

$185^{22}$

18624

25

18726

18828

18929

$190_{32}^{31}$

$191^{33}$

19235

36

19337

38

19439

$195_{41}^{40}$

$196_{43}^{42}$

19744

19846

47

19948

49

20050

$201_{52}^{51}$

20253

20355 56

20457 58

20559

$206_{61}^{66}$

62

63

64

65

All the necessary material having been previously rinsed three times with ultra-pure water in order to prevent any contamination, roughly $5 \mathrm{~kg}$ of snow were melted in one bottle. This snow comes from a snow pit dug in 2012 at the Dome C-Concordia station in Antarctica (Location: $78^{\circ} \mathrm{S}, 106^{\circ} \mathrm{E}$; elevation: $3488 \mathrm{~m}$; mean annual temperature: $\left.-55^{\circ} \mathrm{C}\right)$. It was taken along the first $51 \mathrm{~cm}$ of the $2 \mathrm{~m}$ snow pit and approximatively covers the 2005-2011 time period. The $5 \mathrm{~kg}$ of melted snow were then distributed in 14 different bottles containing approximately $350 \mathrm{~g}$ of sample. For the ion chromatography measurements processed at the IGE laboratory (Institut des Géosciences de l’Environnement, Grenoble, France), and before any chemical preparation, aliquots of $5 \mathrm{~mL}$ were collected from the original sample and from each of the 14 individual samples. Because of the low $\mathrm{Cl}^{-}$content in snow samples ( $\sim 100 \mathrm{ppb}$ ), a carrier has to be added in order to get the minimal $\sim 2$ mg of $\mathrm{Cl}^{-}$needed for AMS measurements. Six of these samples have been spiked with an enriched ${ }^{35} \mathrm{Cl}$ (99.89\%) solution, while a natural $\mathrm{NaCl}$ carrier solution has been added to the eight remaining samples, six with a $\mathrm{NaCl}$ carrier currently used at ASTER as an AMS facility background blank, and two with a new $\mathrm{NaCl}$ carrier never tested before. Six procedural blanks were also prepared, two from the ${ }^{35} \mathrm{Cl}$ enriched spike, two from the ASTER background blank $\mathrm{NaCl}$ carrier and two from the never tested $\mathrm{NaCl}$ carrier (See supplementary table). These 20 samples (14 snow samples +6 blanks) were prepared according to the Conard et al. [23] procedure. After being acidified with a $\mathrm{HNO}_{3}$ solution, the addition of $\mathrm{AgNO}_{3}$ solution into the samples allowed the $\mathrm{AgCl}$ precipitation. After being kept in the dark for two days to complete the precipitation, AgCl was separated with a centrifuge. Each precipitate was dissolved with $\mathrm{NH}_{4}$ and then $1 \mathrm{ml}$ of a saturated $\mathrm{Ba}\left(\mathrm{NO}_{3}\right)_{2}$ solution had been added to remove sulfur contents in the form of $\mathrm{BaSO}_{4}$. After being precipitated again with $\mathrm{HNO}_{3}, \mathrm{AgCl}$ targets were rinsed three times with ultra-pure water, and then dried at $80^{\circ} \mathrm{C}$ for about 48 hours (All data are provided in the supplementary material Sup Table 2).

7 of the 14 samples were measured at DREAMS (samples 1 to 7 ), 3 spiked with the ${ }^{35} \mathrm{Cl}$ enriched solution and 4 complemented with the natural $\mathrm{NaCl}$ carrier (3 with the ASTER tested carrier and 1 with the never tested carrier), and the 7 others were measured at ASTER (samples 8 to 14) (Table 5). One blank sample prepared from these 3 different spike and carrier solutions was also measured on each AMS facility (samples 15 to 20 in the supplementary material Sup Table 2). The ${ }^{36} \mathrm{Cl} /{ }^{35} \mathrm{Cl}$ ratios of the two spiked blanks measured at DREAMS and ASTER are not significantly different. The blanks complemented with natural NaCl carriers show lower ${ }^{36} \mathrm{Cl}$ contribution. Indeed, no ${ }^{36} \mathrm{Cl}$ atoms were detected for the ASTER tested $\mathrm{NaCl}$ carrier, while the ${ }^{36} \mathrm{Cl} /{ }^{35} \mathrm{Cl}$ ratio associated to the never tested carrier is 2 to 8 times lower at ASTER and DREAMS, respectively, than that associated to the spike solution. Despite the higher ${ }^{36} \mathrm{Cl} /{ }^{35} \mathrm{Cl}$ ratio associated to the spiked blank, the signal to noise ratio is always higher than 150, well above the quantification limit. The relevant ${ }^{36} \mathrm{Cl} /{ }^{35} \mathrm{Cl}$ blank values were subtracted from the ${ }^{36} \mathrm{Cl} /{ }^{35} \mathrm{Cl}$ sample ratios to determine the ${ }^{36} \mathrm{Cl}$ concentration of the samples (Table 5). In addition, the natural $\mathrm{Cl}^{-}$concentration determined by ion chromatography was also accounted for the determination of the ${ }^{36} \mathrm{Cl}$ concentrations. 
Natural $\mathrm{Cl}^{-}$concentration measured at the IGE laboratory lead to values ranging from 102 to $106 \mathrm{ppb}$ (with an associated uncertainty of $\sim 5 \%$ ), in agreement with the concentration of $106 \mathrm{ppb}$ measured from the initial sample before it splitting. The chloride concentration derived from the isotopic dilution of the 6 spiked 2 samples can be directly compared to the concentration derived from ion chromatography (samples 1 to 3 at 3 DREAMS and 8 to 10 at ASTER). The natural $\mathrm{Cl}^{-}$concentrations deduced from the ${ }^{35} \mathrm{Cl}$ enriched spiked 5

2126 samples ranges from 95 to $107 \mathrm{ppb}$. Although exhibiting a higher variability than ion chromatography, the $\mathrm{Cl}^{-}$

2137 concentrations obtained from these two independent methods are in agreement implying that both methods are

$214_{10}^{9}$ relevant for total chloride concentration determination at low levels in snow/ice samples (Fig. 3).

$215^{11}$

Because the measurements may be normalized to either the SM-Cl-12 reference material or the KNSTD1600 1613 standard measured together at ASTER, it was thus possible to compare the ${ }^{36} \mathrm{Cl}$ concentrations determined at 14

ASTER against SM-Cl-12 and KNSTD1600 and that determined at DREAMS against SM-Cl-12. Regardless of the normalization scheme and the AMS facility used, the obtained weighted mean ${ }^{36} \mathrm{Cl}$ concentrations from the 7 measurements all satisfy the Chi2 test.

The two weighted means from ASTER normalized against KNSTD1600 (3.76 \pm 0.07$) \times 10^{4}$ at/g and from DREAMS normalized against SM-Cl-12 (3.66 \pm 0.05$) \times 10^{4}$ at/g also agree within uncertainties. This inter comparison validates the use of the SM-Cl-12 as the new reference material replacing the KNSTD1600 standard at ASTER.

27

22428

22529

22631

4 Conclusion.

22733

The long term behavior of the 5 MV French AMS national facility ASTER (CEREGE, Aix en Provence) has been investigated through the analysis of the measurements of the most used chlorine standards and reference materials, KNSTD1600, SM-Cl-12 and SM-CL-13 over a 46 months' time period. The obtained data allow to determine the SM-Cl-12/KNSTD1600 and SM-Cl-13/KNSTD1600 ratios for the three chlorine isotopic ratios $\left({ }^{36} \mathrm{Cl} /{ }^{35} \mathrm{Cl},{ }^{36} \mathrm{Cl} /{ }^{37} \mathrm{Cl}\right.$ and $\left.{ }^{35} \mathrm{Cl} /{ }^{37} \mathrm{Cl}\right)$ which are used to constrain the external uncertainty linked to the ASTER operating conditions and that has to be propagated with the internal uncertainties (counting statistics, standard variability).

Comparison of measured chlorine concentrations from snow samples on two AMS facilities operating at 5MV and $6 \mathrm{MV}$ and normalizing to two different reference materials agree within uncertainties making both reference materials (SM-Cl-12 and KNSTD1600) suitable for ${ }^{36} \mathrm{Cl}$ measurement at ASTER.

$237 \frac{51}{52}$

23853

23955 56

24057 58

24159 valuable assistance. The Dome C snow pit has been dug in the frame of the VANISH project (ANR-0724260 VULN-013) with the logistical support of the French Polar Agency-IPEV. ASTER AMS national facility 
(CEREGE, Aix en Provence) is supported by the INSU/CNRS, the ANR through the "Projets thématiques d'excellence" program for the "Equipements d'excellence" ASTER-CEREGE action and IRD.

This work has been partially funded by CNRS through bilateral France - Germany project PICS 6407. The 2 suggestions of the anonymous reviewer also helped to improve the quality of this paper.

2474

5

2486

7

2498 [1] M. Arnold , S. Merchel, D.L. Bourlès, R. Braucher, L. Benedetti, R.C. Finkel, G. Aumaître, A. Gottdang,

$250_{10}^{9}$ M. Klein, The French accelerator mass spectrometry facility ASTER: Improved performance and 25111 developments,Nucl. Instr. and Meth. in Phys. Res. B, 268, 1954-1959, (2010).

12

25213

25314

25416

25517

$256^{18}$

25719

25821

22

25923

$260_{25}^{24}$

[4] A. Gottdang, D.J.W. Mous, R.G. Haitsma, "The novel HVEE 5 MV Tandetron TM", Nucl. Instr. and Meth. B 190, 177 - 182,(2002).

26127

26228

26329

26431 $265^{32}$

26633

26735

26836

26938

$270^{39}$

$271_{41}^{40}$

27242

27343

27445

$275^{46}$

27648

27749

27850

27952

$280^{53}$

28154

28256

$283 \frac{57}{58}$

28459

28560

28662

28763
64

65

[2] M.G. Klein, A. Gottdang, D.J.W. Mous, D.L. Bourlès, M. Arnold, B. Hamelin, G. Aumaître, R. Braucher , S. Merchel, F. Chauvet, Performance of the HVE 5 MV AMS system at CEREGE using an absorber foil for isobar suppression, Nucl. Instr.and Meth. B 266, 1828-1832, (2008).

[3] M.G. Klein, D.J.W. Mous, A. Gottdang, A compact 1 MV multi-element AMS system. B. Nucl. Instr. and Meth. B 249(1-2), 764-7 (2006)

[4] M. Arnold; G. Aumaître; D. L Bourlès; K. Keddadouche; R. Braucher; R. C Finkel; E. Nottoli ; L. Benedetti; S. Merchel, The French accelerator mass spectrometry facility ASTER after 4 years: Status and recent developments on ${ }^{36} \mathrm{Cl}$ and ${ }^{129} \mathrm{I}$, Nucl. Instr. and Meth. in Phys. Res. B, 294, 24-28, (2013).

[5] R. Finkel, M. Arnold, G. Aumaître, L. Benedetti, D. Bourlès, K. Keddadouche, S. Merchel, Improved

${ }^{36} \mathrm{Cl}$ performance at the ASTER HVE $5 \mathrm{MV}$ accelerator mass spectrometer national facility, Nucl. Instr. and Meth. in Phys. Res. B, 294, 121-125, (2013).

[6] P. Sharma, P. W. Kubik, U. Fehn, H. E. Gove, K. Nishiizumi, D. Elmore, Development of ${ }^{36} \mathrm{C} 1$ standards for AMS, Nucl. Instrum. Meth. B 52, 410-415. (1990).

[7] S. Merchel, W. Bremser, V. Alfimov, M. Arnold, G. Aumaître, L. Benedetti, D. L. Bourlès, M. Caffee, L. K. Fifield, R. C. Finkel, S. P. H. T. Freeman, M. Martschini, Y. Matsushi, D. H. Rood, K. Sasa, P. Steier, T. Takahashi, M. Tamari, S. G. Tims, Y. Tosaki, K. M. Wilcken, S. Xu, Ultra-trace analysis of ${ }^{36} \mathrm{Cl}$ by accelerator mass spectrometry: an interlaboratory study, Anal. Bioanal. Chem., 400, 3125-3132, (2011).

[8] S. Akhmadaliev, R. Heller, D. Hanf, G. Rugel, S. Merchel, The new 6 MV AMS-facility DREAMS at Dresden, Nucl. Instr. and Meth. in Phys. Res. B 294, 5-10, (2013).

[9] G. Rugel, S. Pavetich, S. Akhmadaliev, S.M. Enamorado Baez, A. Scharf, R. Ziegenrücker, S. Merchel, The first four years of the AMS-facility DREAMS: Status and developments for more accurate radionuclide data,Nucl. Instr. and Meth. in Phys. Res. B 370, 94-100, (2016).

[10] S. Pavetich, S. Akhmadaliev, M. Arnold, G. Aumaître, D. Bourlès, J. Buchriegler, R. Golser, K. Keddadouche, M. Martschini, S. Merchel, G. Rugel, P. Steier, Interlaboratory study of the ion source memory effect in ${ }^{36} \mathrm{Cl}$ accelerator mass spectrometry, Nucl. Instr. and Meth. in Phys. Res. B 329, 22-29, (2014). 
[11] G.K. Ward, S.R. Wilson, Procedures for comparing and combining radiocarbon age determinations: a critique,Archeometry 20 (1) (1978) 19-31.

2911

2922

3

2934

2945

2956

2968

2979

29811

29912

13

30014

15

$301_{16}$

30217

$303 \frac{19}{20}$

$304^{21}$

22

30523

24

30625

30726

28

30829

30

30931

$310_{33}^{32}$

$311_{35}^{34}$

$312^{36}$

$313^{38}$

39

31440

41

31542

$316_{44}^{43}$

$317_{46}^{45}$

$318^{47}$

31949

31949

32051

52

32153

32255 56

32357

58

32459

32560

32662

32763

[21] C. Bouchez, , J. Pupier, L. Benedetti, P. Deschamps, V. Guillou, K. Keddadouche, G. Aumaître, M.

Arnold, D. Bourlès, Isotope Dilution-AMS technique for Cl-36 and $\mathrm{Cl}$ determination in low chlorine content waters, Chemical Geology, 404, 62-70, (2015).

[12] K.M. Wilcken, S.P.H.T. Freeman, C. Schnabel, S.A. Binnie, S. Xu, R.J. Phillips, ${ }^{36} \mathrm{Cl}$ accelerator mass spectrometry with a bespoke instrument. Instr. and Meth. in Phys. Res. B:294 , 107 - 114, (2013).

13] E. Nottoli, M. Arnold, G. Aumaître, D.L. Bourlès, K. Keddadouche and M. Suter, The physics behind the sobar separation of ${ }^{36} \mathrm{Cl}$ and ${ }^{10} \mathrm{Be}$ at the French AMS national facility ASTER, Nucl. Instr. and Meth. in Phys. Res. B:294 , 397-402, (2013).

14] Beer, J., Siegenthaler, U., Blinov, A. Temporal ${ }^{10}$ Be variations in ice: Information on solar activity and geomagnetic field intensity, in: Secular Solar and Geomagnetic Varaitions in the Last 10,000 Years. Kluwer Academic Publishers, (1988).

[15] Raisbeck, G.M., Yiou, F., Jouzel, J., Petit, J.R. ${ }^{10} \mathrm{Be}$ and ${ }^{2} \mathrm{H}$ in polar ice cores as a probe of the solar variability’s influence on climate. Phil Trans R Soc Lond A300, 463-470, (1990).

16] Bard, E., Raisbeck, G.M., Yiou, F., Jouzel, J., Solar modulation of cosmogenic nuclide production over the last millenium: comparison between 14C and 10Be records. Earth Planet. Sci. Lett. 150.453-462, (1997).

[17] Beer, J., Johnsen, S., Bonani, G., Finkel, R.C., Langway, J.C.C., Oeschger, H., Stauffer, B., Suter, M., Woelfli, W.. ${ }^{10} \mathrm{Be}$ peaks as time markers in polar ice cores, in: The Last Deglaciation: Absolute and Radiocarbon Chronologies. Bard, E., Broecker, W.S., (1992), p. 344.

18] Yiou, F., Raisbeck, G.M., Baumgartner, S., Beer, J., Hammer, C.U., Johnsen, S., Jouzel, J., Kubik, P.W., Lestringuez, J., Stievenard, M., Suter, M., Yiou, P.,. Beryllium 10 in the Greenland Ice Core Project ice core at Summit, Greenland. J. Geophys. Res. 102, 26783-26794, (1997).

[19] Berggren, A.-M., Beer, J., Possnert, G., Aldahan, A., Kubik, P.W., Christl, M., Johnsen, S.J., Abreu, J., Vinther, B.M.. A 600-year annual 10Be record from the NGRIP ice core, Greenland. Geophys. Res. Lett. 36, (2009).

[20] Baroni, M., Bard, E., Petit, J.R., Magand, O., Bourlès, D.. Volcanic and solar activity, and atmospheric circulation influences on cosmogenic 10Be fallout at Vostok and Concordia (Antarctica) over the last 60 years. Geochim. Cosmochim. Acta 75, 7132-7145, , (2011). 
329 [22] Ginot, P., Dumont, M., Lim, S., Patris, N., Taupin, J.-D., Wagnon, P., Gilbert, A., Arnaud, Y., Marinoni, 3301 A., Bonasoni, P., Laj, P.. A 10 year record of black carbon and dust from a Mera Peak ice core (Nepal):

3312 variability and potential impact on melting of Himalayan glaciers. The Cryosphere 8, 1479-1496, (2014).

$332 \begin{aligned} & 4 \\ & 5\end{aligned}$

6

3337 [23] Conard, N.J., Elmore, D., Kubik, P.W., Gove, H.E., Tubbs, L.E., Chrunyk, B.A., Wahlen, M. The $334{ }_{9}^{8}$ chemical preparation of $\mathrm{AgCl}$ for measuring ${ }^{36} \mathrm{Cl}$ in polar ice with accelerator mass spectrometry. $335_{11}^{10}$ Radiocarbon 28, 556-560, (1986).

$336^{12}$

Figure and tables captions:

3919 Fig 1 Probability distribution functions of the ${ }^{36} \mathrm{Cl} /{ }^{35} \mathrm{Cl},{ }^{36} \mathrm{Cl} /{ }^{37} \mathrm{Cl}$ and ${ }^{35} \mathrm{Cl} /{ }^{37} \mathrm{Cl}$ ratios of the SM-Cl-12 $340_{21}^{20}$ reference material measured against the KNSTD1600 standard. The standard deviations include the counting 34122 statistics of the sample and the variability associated to the KNSTD1600 ${ }^{36} \mathrm{Cl} /{ }^{35} \mathrm{Cl},{ }^{36} \mathrm{Cl} /{ }^{37} \mathrm{Cl}$ and ${ }^{35} \mathrm{Cl} /{ }^{37} \mathrm{Cl}$ 34223 ratios during the considered batch.

$343{ }_{26}^{25}$ Fig 2 Probability distribution functions of the ${ }^{36} \mathrm{Cl} /{ }^{35} \mathrm{Cl},{ }^{36} \mathrm{Cl} /{ }^{37} \mathrm{Cl}$ and ${ }^{35} \mathrm{Cl} /{ }^{37} \mathrm{Cl}$ ratios of the SM-Cl-13 34427 measured against the KNSTD1600 chlorine standard. The standard deviations include the counting statistics $345_{29}^{28}$ of the sample and the variability associated to the KNSTD $1600{ }^{36} \mathrm{Cl} /{ }^{35} \mathrm{Cl},{ }^{36} \mathrm{Cl} /{ }^{37} \mathrm{Cl}$ and ${ }^{35} \mathrm{Cl} /{ }^{37} \mathrm{Cl}$ ratios during 34630 the considered batch.

31

34732 33 34834 34936 35038 $351_{40}^{39}$

35241 $353_{43}^{42}$ 44 35445 $355^{46}$ 35648 49 35750 51 35852 $359_{54}^{53}$ 36055
56 $361_{57}^{56}$ 36258
59 36359 36461

Fig. 3: Total $\mathrm{Cl}^{-}$concentration determined from ion chromatography (triangle) [21] compared with isotopic dilution method from spiked samples measured at DREAMS normalized to SM-Cl-12, (Black squares, samples 1, 2 and 3) and at ASTER (samples 8, 9 and 10). Stars and dots represent the values measured at ASTER and normalized to KNSTD1600 and SM-Cl-12 respectively.

Table 1: Typical specifications for chlorine measurements at ASTER and at DREAMS AMS (modified from [1] and [7]). Both facilities use a modified HVE source SO110.

Table 2: Data treatment of the SM-Cl-12 and SM-Cl-13 reference material measurements. The Chi2 test is passed when the Experimental 95\% Ch12 value is lower that the theoretical one. To pass the test, external uncertainties have to be added ( see table 3).

Table 3: ${ }^{36} \mathrm{Cl} /{ }^{35} \mathrm{Cl},{ }^{36} \mathrm{Cl} /{ }^{37} \mathrm{Cl}$ and ${ }^{35} \mathrm{Cl} /{ }^{37} \mathrm{Cl}$ SM-Cl-X isotopic ratios determined by multiplying the SM-ClX/KNSTD1600 mean ratio (this study, table 2) by their corresponding KNSTD1600 values (column 2), for SM-Cl-12 and SM-Cl-13. Only analytical uncertainties are reported here (no external uncertainty). Corresponding ratios presented by Merchel et al. (2011) [6] are presented. ASTER external uncertainty is the uncertainty to be added to the analytical uncertainties (counting statistics + variability of the standard during the batch) to make all the SM-Cl-12/KNSTD1600 and SM-Cl-13/KNSTD1600 ratios belonging to the same population. 
365 Table 4: Measured SM-Cl-12 and SM-Cl-13 ${ }^{36} \mathrm{Cl} /{ }^{\text {Total }} \mathrm{Cl}$ isotopic ratios compared to the those published by 366 Merchel et al. (2011) [6]

367

$368{ }_{3}^{2}$ Table 5: Concentrations in $10^{4}$ at/g of the ice samples measured at ASTER and normalized with KNSTD1600

3694 and SM-Cl-12, and measured at DREAMS against SM-Cl-12. (Uncertainties take into account the counting

$370{ }_{6}^{5}$ statistics, variability on standard measurements during the entire batch and the uncertainty linked to the

3717 standards that are $1.30 \%$ and $1.48 \%$ for KNSTD1600 and SM-Cl-12 ${ }^{36} \mathrm{Cl} /{ }^{35} \mathrm{Cl}$ ratios, respectively). All data

3728 measurements and associated blanks are presented in the supplementary material.

$373_{11}^{10}$

12

37413

14

37515

16

$376^{17}$

18

7719

21

22

23

24

25

26

27

28

29

30

31

32

33

34

35

36

37

38

39

40

41

42

43

44

45

46

47

48

49

50

51

52

53

54

55

56

57

58

59

60

61

62

63

64

65

Supplement Material available here:

https://www.dropbox.com/s/3l2x7w81oqnqt2e/SupplementTable-Braucher\%20et\%20al.xlsx?dl=0

SupTable 1: Measured SM-Cl-X / KNSTD1600 ratios

SupTable 2: Snow sample preparation (carrier, spike) and measurements. 
Table 1: Typical specifications for chlorine measurements at ASTER and at DREAMS AMS (modified from [1] and [7]). Both facilities use a modified HVE source SO110.

\begin{tabular}{|c|c|c|c|c|c|c|}
\hline & Extraction as & $\begin{array}{c}{ }^{35} \mathrm{Cl} \\
\text { currents } \\
(\mu \mathrm{A})\end{array}$ & $\begin{array}{c}\text { Terminal } \\
\text { Voltage }(\mathrm{MV})\end{array}$ & $\begin{array}{c}\text { Charge state } \\
\text { after gaz stripper }\end{array}$ & $\begin{array}{c}\text { Charge state after } \\
\text { absorber foil }\end{array}$ & $\begin{array}{c}\text { Background } \\
\left(10^{-15}\right)\end{array}$ \\
\hline ASTER & $\mathrm{Cl}^{-}$at $29.5 \mathrm{kV}$ & $15-25$ & 5 & $5^{+}$ & $10^{+}$ & 0.28 \\
\hline DREAMS & $\mathrm{Cl}^{-}$at $25 \mathrm{kV}$ & $20-30$ & 6 & $5^{+}$ & $11^{+}$ & 0.4 \\
\hline
\end{tabular}


Table 2: Data treatment of the SM-Cl-12 and SM-Cl-13 reference material measurements. The Chi2 test is passed when the Experimental 95\% Ch12 value is lower that the theoretical one. To pass the test, external uncertainties have to be added ( see table 3).

\begin{tabular}{|c|c|c|c|c|c|c|}
\hline & \multicolumn{3}{|c|}{ SM-Cl-12 } & \multicolumn{3}{|c|}{ SM-Cl-13 } \\
\hline & ${ }^{36} \mathrm{Cl} /{ }^{35} \mathrm{Cl}$ & ${ }^{36} \mathrm{Cl} /{ }^{37} \mathrm{Cl}$ & ${ }^{35} \mathrm{Cl} /{ }^{37} \mathrm{Cl}$ & ${ }^{36} \mathrm{Cl} /{ }^{35} \mathrm{Cl}$ & ${ }^{36} \mathrm{Cl} /{ }^{37} \mathrm{Cl}$ & ${ }^{35} \mathrm{Cl} /{ }^{37} \mathrm{Cl}$ \\
\hline Number of cathodes & \multicolumn{3}{|c|}{189} & \multicolumn{3}{|c|}{31} \\
\hline $\begin{array}{c}\text { Mean ratio } \\
\text { SM-Cl-X/KNSTD1600 }\end{array}$ & 0.686 & 0.685 & 1.000 & 0.071 & 0.071 & 0.999 \\
\hline Standard deviation & 0.027 & 0.023 & 0.020 & 0.005 & 0.006 & 0.006 \\
\hline Mean standard error & 0.002 & 0.002 & 0.001 & 0.001 & 0.001 & 0.001 \\
\hline $\begin{array}{c}\text { Theoretical } \\
\text { 95\% Chi-square }\end{array}$ & \multicolumn{3}{|c|}{220.99} & \multicolumn{3}{|c|}{43.77} \\
\hline $\begin{array}{c}\text { Experimental } \\
\text { 95\% Chi square }\end{array}$ & 634.89 & 474.53 & 2980.65 & 51.67 & 53.38 & 622.4 \\
\hline
\end{tabular}


Table 3: ${ }^{36} \mathrm{Cl} /{ }^{35} \mathrm{Cl},{ }^{36} \mathrm{Cl} /{ }^{37} \mathrm{Cl}$ and ${ }^{35} \mathrm{Cl} /{ }^{37} \mathrm{Cl}$ SM-Cl-X isotopic ratios determined by multiplying the SM-Cl-X/KNSTD1600 mean ratio (this study, table 2) by their corresponding KNSTD1600 values (column 2), for SM-Cl-12 and SM-Cl-13. Only analytical uncertainties are reported here (no external uncertainty). Corresponding ratios presented by Merchel et al. (2011) [6] are presented. ASTER external uncertainty is the uncertainty to be added to the analytical uncertainties (counting statistics + variability of the standard during the batch) to make all the SM-Cl-12/KNSTD1600 and SM-Cl-13/KNSTD1600 ratios belonging to the same population.

\begin{tabular}{|l|c|c|c|c||c|c|c|}
\hline & $\begin{array}{c}\text { KNSTD1600 } \\
\left(10^{-12}\right)^{*}\end{array}$ & $\begin{array}{c}\text { SM-Cl-12 }\left(10^{-12}\right)^{*} \\
\text { This Study }\end{array}$ & $\begin{array}{c}\text { SM-Cl-12 }\left(10^{-12}\right)^{*} \\
{[6]}\end{array}$ & $\begin{array}{c}\text { ASTER } \\
\text { Ext. Uncert. }\end{array}$ & $\begin{array}{c}\text { SM-Cl-13 }\left(10^{-13}\right)^{*} \\
\text { This Study }\end{array}$ & $\begin{array}{c}\text { SM-CL-13 }\left(10^{-13}\right)^{*} \\
{[6]}\end{array}$ & $\begin{array}{c}\text { ASTER } \\
\text { Ext. Uncert. }\end{array}$ \\
\hline${ }^{36} \mathrm{Cl} /{ }^{35} \mathrm{Cl}$ & 2.2112 & $1.446 \pm 0.04$ & $1.428 \pm 0.021$ & $2.74 \%$ & $1.476 \pm 0.033$ & $1.515 \pm 0.029$ & $2.06 \%$ \\
\hline${ }^{36} \mathrm{Cl} /{ }^{37} \mathrm{Cl}$ & 6.603 & $4.519 \pm 0.097$ & $4.466 \pm 0.066$ & $2.13 \%$ & $4.596 \pm 0.106$ & $4.738 \pm 0.091$ & $2.31 \%$ \\
\hline${ }^{35} \mathrm{Cl} /{ }^{37} \mathrm{Cl}$ & 3.127 & $3.126 \pm 0.000$ & 3.127 & $1.62 \%$ & $3.126 \pm 0.049$ & 3.127 & $1.58 \%$ \\
\hline
\end{tabular}

*: $10^{-x}$ factor not applicable for the ${ }^{35} \mathrm{Cl} /{ }^{37} \mathrm{Cl}$ 
Table 4: Measured SM-Cl-12 and SM-Cl-13 ${ }^{36} \mathrm{Cl} /{ }^{\text {Total }} \mathrm{Cl}$ isotopic ratios compared to the those published by Merchel et al. (2011) [6]

\begin{tabular}{|c|c|c|}
\hline & \multicolumn{2}{|c|}{${ }^{36} \mathrm{Cl} /(\mathrm{Total} \mathrm{Cl})$} \\
\cline { 2 - 3 } & SM-Cl-12 $\left(10^{-12}\right)$ & $\mathrm{SM}-\mathrm{Cl}-13\left(10^{-13}\right)$ \\
\hline This study & $1.096 \pm 0.03$ & $1.118 \pm 0.010$ \\
\hline Merchel et al. (2011) [6] & $1.082 \pm 0.016$ & $1.148 \pm 0.022$ \\
\hline $\begin{array}{c}\text { ASTER old source head } \\
\text { for comparison [6] })\end{array}$ & $1.113 \pm 0.040$ & $1.265 \pm 0.055$ \\
\hline
\end{tabular}


Table 5: Concentrations in $10^{4}$ at/g of the ice samples measured at ASTER and normalized with KNSTD1600 and SM-Cl-12, and measured at DREAMS against SM-Cl-12. (Uncertainties take into account the counting statistics, variability on standard measurements during the entire batch and the uncertainty linked to the standards that are $1.30 \%$ and $1.48 \%$ for KNSTD1600 and SM-Cl-12 ${ }^{36} \mathrm{Cl} /{ }^{35} \mathrm{Cl}$ ratios, respectively). All data measurements and associated blanks are presented in the supplementary material.

\begin{tabular}{|c|c|c|c|c|c|c|c|c|}
\hline Samples & 8 (spiked) & 9 (spiked) & 10 (spiked) & 11 (carrier) & 12 (carrier) & 13 (carrier) & 14 (carrier) & $\begin{array}{c}\text { Weighted Mean } \\
\text { Chi2 (Samples / } \\
\text { Theoretical) }\end{array}$ \\
\hline $\begin{array}{c}\text { Aster } \\
\text { (KNSTD1600) }\end{array}$ & $\begin{array}{c}4.06 \pm \\
0.15\end{array}$ & $\begin{array}{c}3.83 \pm \\
0.15\end{array}$ & $3.91 \pm 0.14$ & $3.73 \pm 0.14$ & $3.65 \pm 0.14$ & $3.5 \pm 0.13$ & $3.76 \pm 0.14$ & $3.76 \pm 0.07$ \\
\hline $\begin{array}{c}\text { Aster } \\
(\text { SM-Cl-12) }\end{array}$ & $\begin{array}{c}3.99 \pm \\
0.14\end{array}$ & $\begin{array}{c}3.76 \pm \\
0.14\end{array}$ & $3.84 \pm 0.14$ & $3.67 \pm 0.13$ & $3.59 \pm 0.13$ & $3.44 \pm 0.12$ & $3.70 \pm 0.14$ & $3.70 \pm 0.05$ \\
\hline
\end{tabular}

\begin{tabular}{|c|c|c|c|c|c|c|c|c|c|}
\hline Samples & 1 (spiked) & 2 (spiked) & 3 (spiked) & 4 (carrier) & 5 (carrier) & 6 (carrier) & 7 (carrier) & Weighted Mean & $\begin{array}{c}\text { Chi2 (Samples / } \\
\text { Theoretical) }\end{array}$ \\
\hline $\begin{array}{c}\text { Dreams } \\
\text { (SM-Cl-12) }\end{array}$ & $\begin{array}{c}3.69 \pm \\
0.13\end{array}$ & $\begin{array}{c}3.96 \pm \\
0.13\end{array}$ & $3.39 \pm 0.17$ & $3.85 \pm 0.13$ & $3.60 \pm 0.13$ & $3.66 \pm 0.13$ & $3.72 \pm 0.13$ & $3.66 \pm 0.05$ & $9.52 / 12.59$ \\
\hline
\end{tabular}





\begin{tabular}{|c|c|c|c|c|c|c|}
\hline cathode & ${ }^{36} \mathrm{Cl} /{ }^{35} \mathrm{Cl}$ & $\Delta^{36} \mathrm{Cl} /{ }^{35} \mathrm{Cl} \%$ & ${ }^{36} \mathrm{Cl} /{ }^{37} \mathrm{Cl}$ & $\Delta^{36} \mathrm{Cl} /{ }^{37} \mathrm{Cl} \%$ & ${ }^{35} \mathrm{Cl} /{ }^{37} \mathrm{Cl}$ & $\Delta^{3} \mathrm{Cl} /{ }^{37} \mathrm{Cl} \%$ \\
\hline AHQV & 0.6119 & 2.20 & 0.6653 & 2.19 & 1.0881 & 0.51 \\
\hline AGFP & 0.6276 & 2.17 & 0.6308 & 2.05 & 1.0064 & 0.26 \\
\hline AGFP & 0.6276 & 2.17 & 0.6308 & 2.05 & 1.0064 & 0.26 \\
\hline AHHD & 0.6302 & 3.97 & 0.6281 & 3.17 & 0.9954 & 1.15 \\
\hline $\mathrm{AHGZ}$ & 0.6343 & 1.93 & 0.6415 & 1.93 & 1.0021 & 0.82 \\
\hline AHFY & 0.6406 & 2.00 & 0.6388 & 2.00 & 0.9882 & 0.72 \\
\hline AGYT & 0.6437 & 2.52 & 0.6691 & 2.52 & 1.0375 & 0.35 \\
\hline AHGY & 0.6444 & 1.89 & 0.6472 & 1.89 & 0.9953 & 1.39 \\
\hline AGUU & 0.6473 & 1.83 & 0.6471 & 1.83 & 0.9996 & 0.08 \\
\hline AFZH & 0.6488 & 2.58 & 0.6778 & 2.58 & 1.0557 & 0.71 \\
\hline AFZH & 0.6488 & 2.58 & 0.6778 & 2.58 & 1.0557 & 0.71 \\
\hline AGQK & 0.6489 & 2.35 & 0.6521 & 1.85 & 1.0222 & 1.31 \\
\hline AGXM & 0.6506 & 2.16 & 0.6827 & 2.16 & 1.0513 & 1.03 \\
\hline AHQC & 0.6508 & 3.40 & 0.6567 & 3.13 & 1.0065 & 0.39 \\
\hline AGPS & 0.6510 & 1.77 & 0.6506 & 1.86 & 1.0015 & 0.22 \\
\hline AGYU & 0.6511 & 2.14 & 0.6841 & 2.14 & 1.0486 & 0.56 \\
\hline AHCF & 0.6511 & 3.01 & 0.6595 & 1.91 & 1.0032 & 0.18 \\
\hline AHYV & 0.6516 & 3.05 & 0.6581 & 3.05 & 1.0060 & 0.36 \\
\hline AIAF & 0.6517 & 3.89 & 0.6499 & 3.92 & 0.9984 & 0.52 \\
\hline AIAC & 0.6524 & 3.81 & 0.6554 & 3.85 & 1.0058 & 0.80 \\
\hline AFZT & 0.6531 & 3.13 & 0.6679 & 3.12 & 1.0520 & 0.61 \\
\hline AFZT & 0.6531 & 3.13 & 0.6679 & 3.12 & 1.0520 & 0.61 \\
\hline AIAE & 0.6544 & 3.97 & 0.6619 & 4.00 & 1.0126 & 0.60 \\
\hline AGEZ & 0.6553 & 1.62 & 0.6422 & 1.78 & 0.9732 & 0.77 \\
\hline AGEZ & 0.6553 & 1.62 & 0.6422 & 1.78 & 0.9732 & 0.77 \\
\hline AHCE & 0.6555 & 3.13 & 0.6590 & 2.10 & 0.9958 & 0.24 \\
\hline $\mathrm{AHPI}$ & 0.6561 & 2.04 & 0.6832 & 2.04 & 1.0330 & 2.23 \\
\hline AHPF & 0.6566 & 1.84 & 0.6621 & 1.86 & 1.0081 & 0.65 \\
\hline AHYU & 0.6584 & 3.17 & 0.6620 & 3.19 & 1.0015 & 0.35 \\
\hline AGRL & 0.6585 & 1.90 & 0.6584 & 1.90 & 0.9998 & 0.10 \\
\hline AGQS & 0.6590 & 1.91 & 0.6648 & 1.91 & 1.0119 & 0.53 \\
\hline AGDT & 0.6592 & 2.55 & 0.6490 & 2.29 & 0.9779 & 0.74 \\
\hline AGDT & 0.6592 & 2.55 & 0.6490 & 2.29 & 0.9779 & 0.74 \\
\hline $\mathrm{AHCD}$ & 0.6619 & 3.05 & 0.6667 & 1.99 & 0.9975 & 0.52 \\
\hline AGQQ & 0.6625 & 2.00 & 0.6672 & 2.00 & 1.0102 & 0.51 \\
\hline AHFR & 0.6641 & 2.49 & 0.6599 & 2.56 & 0.9914 & 0.60 \\
\hline AGQR & 0.6647 & 1.92 & 0.6526 & 1.92 & 0.9848 & 0.48 \\
\hline $\mathrm{AHPL}$ & 0.6652 & 1.77 & 0.6621 & 1.77 & 0.9924 & 0.27 \\
\hline AGYG & 0.6656 & 1.86 & 0.6597 & 1.88 & 0.9909 & 0.61 \\
\hline AHQY & 0.6656 & 2.62 & 0.6568 & 1.90 & 0.9874 & 2.15 \\
\hline AHPW & 0.6664 & 3.23 & 0.6640 & 3.40 & 0.9998 & 0.32 \\
\hline AGFQ & 0.6669 & 2.02 & 0.6660 & 1.89 & 1.0001 & 0.40 \\
\hline AGFQ & 0.6669 & 2.02 & 0.6660 & 1.89 & 1.0001 & 0.40 \\
\hline AGDS & 0.6674 & 2.63 & 0.6840 & 2.38 & 1.0179 & 1.63 \\
\hline AGDS & 0.6674 & 2.63 & 0.6840 & 2.38 & 1.0179 & 1.63 \\
\hline AHHB & 0.6681 & 4.07 & 0.6806 & 3.30 & 1.0173 & 1.15 \\
\hline $\mathrm{AHCB}$ & 0.6683 & 2.15 & 0.6712 & 2.14 & 1.0040 & 0.30 \\
\hline AHQR & 0.6684 & 3.34 & 0.6680 & 3.07 & 0.9968 & 0.43 \\
\hline AGYD & 0.6685 & 1.56 & 0.6676 & 1.56 & 1.0006 & 0.22 \\
\hline AHFW & 0.6697 & 2.07 & 0.6728 & 1.80 & 1.0061 & 0.51 \\
\hline AGWU & 0.6697 & 2.09 & 0.6725 & 2.09 & 1.0042 & 0.12 \\
\hline AGDR & 0.6699 & 2.48 & 0.6758 & 2.22 & 1.0019 & 0.75 \\
\hline AGDR & 0.6699 & 2.48 & 0.6758 & 2.22 & 1.0019 & 0.75 \\
\hline
\end{tabular}

\begin{tabular}{|c|c|}
\hline cathode & ${ }^{\mathbf{3 6}} \mathbf{C l} /{ }^{\mathbf{3 5}} \mathbf{C l}$ \\
\hline AHFL & 0.0635 \\
\hline AFWV & 0.0642 \\
\hline AFYS & 0.0659 \\
\hline AHPU & 0.0659 \\
\hline AHBY & 0.0663 \\
\hline AHFM & 0.0664 \\
\hline AFYG & 0.0666 \\
\hline AHGU & 0.0669 \\
\hline AGEU & 0.0675 \\
\hline AFXV & 0.0678 \\
\hline AHFM & 0.0681 \\
\hline AGDB & 0.0682 \\
\hline AHGV & 0.0687 \\
\hline AHBX & 0.0690 \\
\hline AGJZ & 0.0692 \\
\hline AFXH & 0.0694 \\
\hline AHYK & 0.0695 \\
\hline AHOM & 0.0699 \\
\hline AHOL & 0.0707 \\
\hline AHPT & 0.0707 \\
\hline AGEV & 0.0724 \\
\hline AHPS & 0.0725 \\
\hline AGDQ & 0.0726 \\
\hline AHRK & 0.0738 \\
\hline AHYI & 0.0739 \\
\hline AGAC & 0.0766 \\
\hline AHRL & 0.0772 \\
\hline AGJY & 0.0774 \\
\hline AIAA & 0.0816 \\
\hline AHRM & 0.0825 \\
\hline AFZQ & 0.0838 \\
\hline &
\end{tabular}



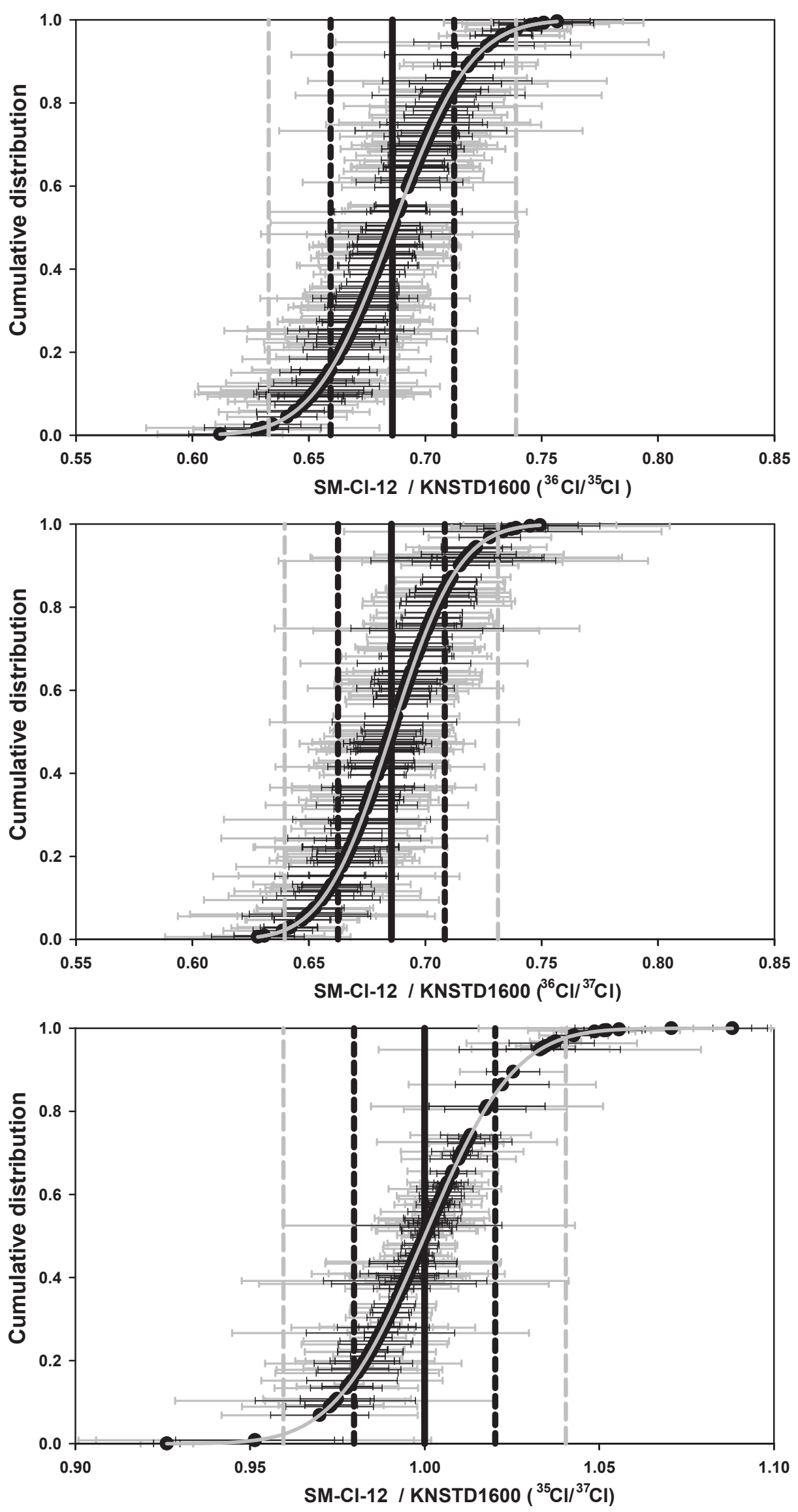

- Raw measurements $(n=189)$ Black error bars : 1 sigma; Grey error bars : 2 sigmas
- 1 sigma on the distribution 2 sigmas on the distribution Mean of the distribution Cumulative distribution function 

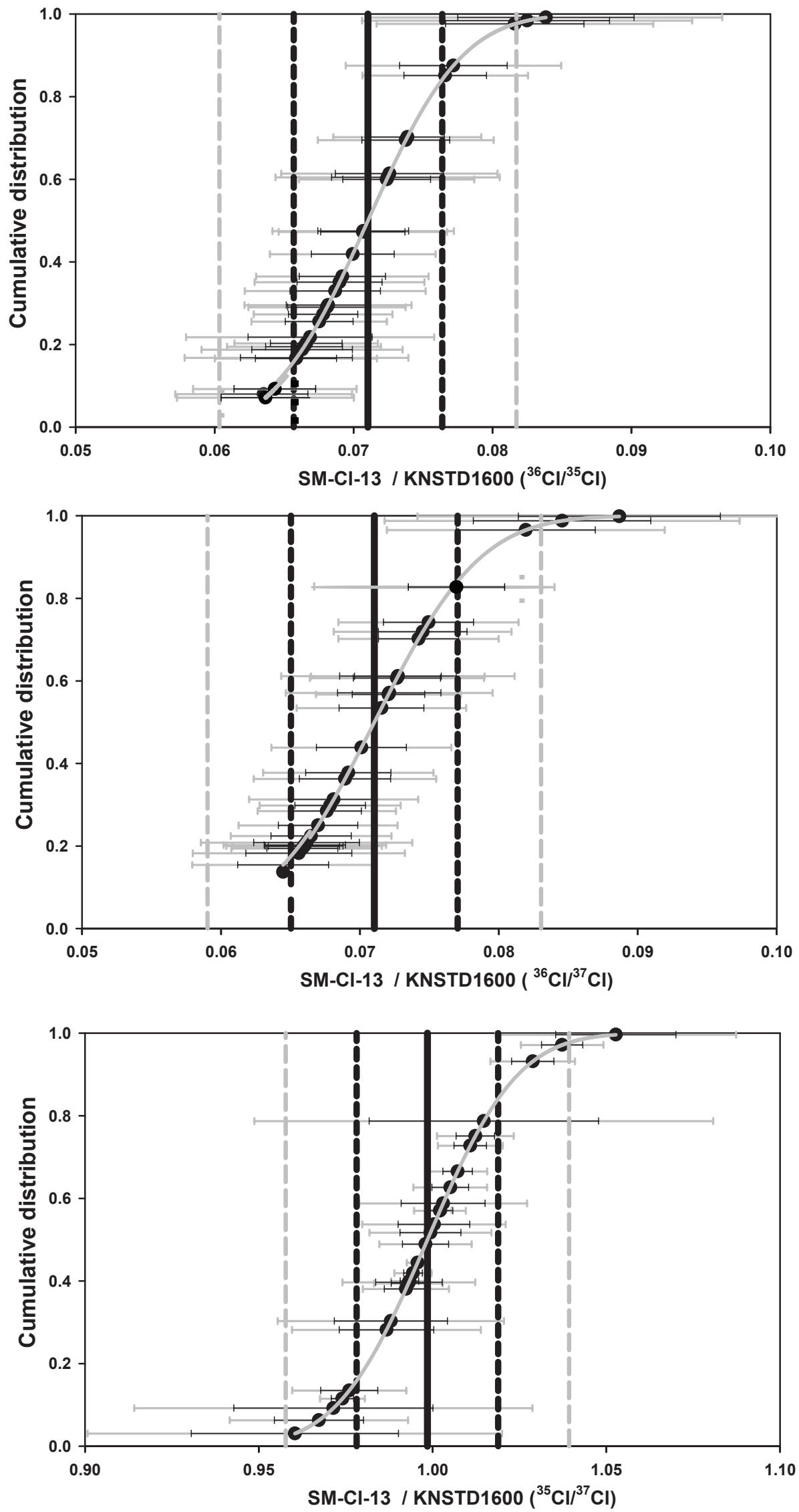

- Raw measurements ( $n=31)$ Black error bars : 1 sigma; Grey error bars : 2 sigmas
1 sigma on the distribution 2 sigmas on the distribution Mean of the distribution Cumulative distribution function 


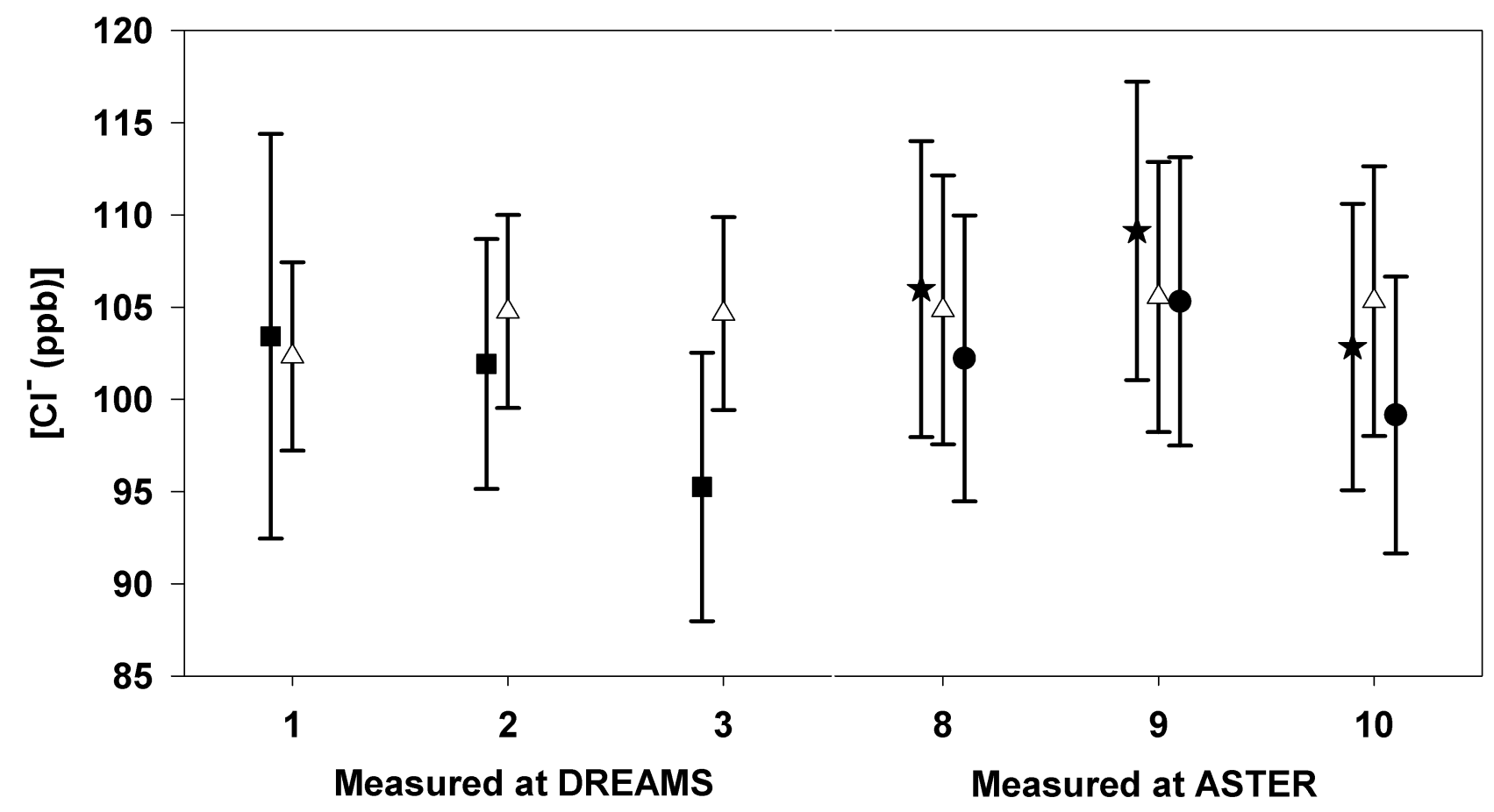

